Resumen por el autor, John Shelton Horsley, Jr., Universidad de Virginia.

Descripción de un perro con seis patas.

El presente trabajo es una descripción detallada de la anatomía externa e interna de una perra jóven que poseía un par adicional de patas posteriores bastante normales y colocadas simétricamente. Este mónstruo presentaba un par de pelvis casi normales fusionadas entre sí, una cloaca en el lado derecho, ano $\mathrm{y}$ vagina separados en el lado izquierdo, dos vejigas urinarias, un solo riñón, un uréter impar en conexión con la vejiga izquierda, un solo intestino delgado, dos colon, dos ciegos con sus correspondientes apéndices, glándulas suprarrenales pares y dos úteros provistos cada uno de un tubo uterino y un ovario. Las tibias de las patas supernumerarias estaban fusionadas.

Translation by José F. Nonidez

Cornell University Medical College, N. $Y$. 


\title{
A DESCRIPTION OF A SIX-LEGGED DOG
}

\author{
JOHN SHELTON HORSLEY, JR. \\ Department of Anatomy, University of Virginia \\ SIXTEEN FIGURES
}

On January 11, 1919, Mr. John R. Raines, a farmer living near the University, brought to Prof. H. E. Jordan's laboratory a dead female dog with an extra pair of hind legs. The thoracic and abdomnial cavities were opened and the dog at once placed in a. 10 per cent solution of formalin. This specimen was subsequently turned over to me for study and description. The work was done in the Laboratory of Histology and Embryology under the supervision of Professor Jordan, to whom I am greatly indebted for the privilege.

From Mr. Raines were secured the following data: The dog was born October 7, 1918; died from exposure to cold the night of January 9, 1919. Her father was a shepherd, her mother a bull-terrier; both parents were apparently normal. The litter included in addition to this abnormal individual one normal brother and three normal sisters. The six-legged puppy appeared in life otherwise normal and healthy, and was apparently but little inconvenienced in walking and running by the extra pair of legs, which she carried slightly raised above the ground. The unpaired tail was apparently under perfect control.

\section{EXTERNAL APPEARANCE}

As regards the shape and general appearance of the head this dog more nearly resembled a fox-terrier, and she was about the size of this type of dog (fig. 1). With the exception of the nipples, she appeared normal cephalad of the umbilicus. With the exception of the tail and anus, she was double caudad of this point. 
Closer examination revealed the following details: The leg, vagina, anus, and tail of the left side were displaced about $1 \mathrm{~cm}$. laterad of their normal relative position with respect to the vertebral column. The sagittal plane of the proximal portion of the tail made an angle of 25 degrees with that of the vertebral column. The right leg was displaced slightly forward and dextrad of its normal position. It was slightly smaller than the left leg and presented a rather undeveloped appearance, especially in the size of the thigh muscles. Between these two legs hung the extra pair of legs. The pair was inclined a little to the right of the medial line and it was enveloped in a common integument as far distally as the ankles. The members of the pair were of approximately equal size and represented genuine hind legs. Barring a very slight ventral bend at the level of the knees, the pair was extended in a straight line and it was placed in such a way that the pads of the feet faced toward the ground when the dog was standing. The pair measured $18.5 \mathrm{~cm}$. from the heads of the femurs to the tips of the toes. These extra legs were only slightly more slender and shorter than the other two hind legs. Palpation indicated a fusion of the tibiae, a conclusion confirmed by roentgenograms (figs. 2 and 3 ) and subsequent dissection. The extra legs articulated with the medial surfaces of the opposite halves of the paired pelves slightly forward, and to the right, of the root of the tail. There was no second tail or anus, but there was a second set of external genitalia $2 \mathrm{~cm}$. below and to the right of the articulations of the extra pair of legs. The vertebral column in the region of the sacrum seemed abnormally wide on the right side and presented abnormal landmarks, description of which will be reverted to subsequently. Just below the right side of the double knee there was a roughened scarlike area, whose significance will also be indicated below. 


\section{INTERNAL ANATOMY}

\section{Osteology}

The vertebral column contained the usual number of vertebrae, namely seven cervical, thirteen thoracic, seven lumbar, three sacral, and nineteen caudal (fig. 2). It remained single throughout and was normal as far as the seventh lumbar vertebra, which latter was normal on the left side, but presented a large wellrounded mammillary process that was twisted dorsally and slightly caudally extending on the same level with that of the corresponding vertebral spine. The sacrum was very slightly bent to the left. On the right the articular surface of the first sacral vertebra was turned dorsally, and accordingly produced a slight elevation. There was also on the right side an oblong, irregular plate of bone that measured $10 \mathrm{~mm}$. in length, $7 \mathrm{~mm}$. in thickness, and $6 \mathrm{~mm}$. in the vertical plane (fig. $4, M$ ). It was fused with the first and second sacral vertebrae, and represented a second deformed sacrum. On the left side the sacropelvic articulation was normal with the exception of a small piece of bone, $8 \mathrm{~mm}$. in length, which jutted out caudally from the left ilium at the level of the sacrum and was fused with the second and third sacral vertebrae. There was a gentle curve to the left, formed by the first three caudal vertebrae, the first of which articulated on its right side with the base of the fused ilia. The remaining caudal vertebrae were normal.

Two pelves were present (fig. 3). At first observation there seemed to be a smaller medial pelvis fused dorsally to a larger and practically normal ventral pelvis; but after closer examination of all of the related structures the conclusion was reached that the condition was one of lateral fusion between a right and left pelvis. The course of the unpaired sciatic nerve is the only obstacle to the latter interpretation. The right and left lateral ilia were of normal size (figs. 4 and 5). The left ilium articulated with the sacrum of the left side in the usual manner, with the exception of the intervention of a small spur of bone extending caudally from it. This has already been described. The crest of the right ilium was displaced cephalicly $1 \mathrm{~cm}$. and dorsally 
$3 \mathrm{~mm}$. A small triangular piece of bone, $1.5 \mathrm{~cm}$. in length, articulated with the right deformed sacrum by a number of strong ligaments forming an amphiarthrosis (fig. $4 \mathrm{~N}$ ). The crests of these lateral ilia were about $6 \mathrm{~mm}$. further apart than they should have been if the right had its normal position and the two considered part of one pelvis.

The right and left medial ilia were fused to form one bone which presented a dorsally protruding crest (fig. 4). This fused medial ilium was approximately a third the size of the normal lateral ilia. The vestigial right sacrum was fused with the base of the medial fused ilium. These two structures were continuous on the ventral surface, but dorsally there was a depression partially separating them. On the left the base of the fused ilium was joined to the third sacral vertebra by a synchondrosis, and with the first (proximal) caudal vertebra by a syndesmosis. This fusion of the ilia had brought the two medial acetabula so close together on the dorsal surface that they nearly touched each other (fig. 5). The long axis of this medially fused ilial portion of the compound pelvis made a 15 degree angle with the midline on the right side. If considered as a dorsally interpolated pelvis, it would be about half the size of the larger pelvis.

The two medial ischia formed a basin, which was open dorsocaudally and closed ventrocephalicly, presenting on each side the relatively high crests of the two medial tubera ischii. The basin measured $3.7 \mathrm{~cm}$. from crest to crest (fig. 5). In this basin lay the necks and proximal fourths of the femurs of the extra two legs, along with that portion of the heads that did not enter directly into the hip-joints (fig. 4). The two obturator foramina opened ventrocephalicly through each side. They were completely closed by thin ligamentous bands and were of about half the normal size. Caudal to the fusion of the medial ilia, and also to the acetabula, there was a very firm union between the right and left pelves along the whole length of the pubo-ischial symphysis of each (fig. 5). This line of fusion would call for the same description whether the fused pelves were interpreted as right and left or dorsal and ventral components. 
The heads of the femurs of the extra two legs were about $1 \mathrm{~mm}$. apart and articulated with the two medial acetabula, each forming an enarthrosis. The articulations were alike on both sides, and normal to the extent that they formed ball-and-socket joints, with synovial bursae, ligamentous capsules, etc. There was a slight twisting, however; produced by their abnormal positions. All of the structures that entered into these articulations were of approximately half the size of the corresponding structures of the normal right and left lateral hip-joint. The movements of these articulations were limited practically to a dorsoventral action due to the fusion of the tibiae of the two extra legs (fig. 3).

The right and left lateral ischia were of normal size, but were slightly twisted laterally, the right more so than the left. The crest of the right lateral tuber ischii was $1 \mathrm{~cm}$. laterad of that of the right medial tuber ischii at the widest point (fig. 4). The right colon, vagina, and urethra united within the basin formed by these ischia into a cloaca (fig. 12). The opening of this basin was the pelvic mouth of the right pelvis. The corresponding crests of the left side were $2 \mathrm{~cm}$. apart at their widest points and formed a somewhat less constricted basin for the left vagina. The aperture of this basin was the pelvic mouth of the left pelvis (fig. 5).

The bones of the right and left lateral legs were normal. Those of the extra two medial legs were very slightly shorter and slightly more slender than the lateral ones, as may be seen in figure 3 . The tibiae of the supernumerary legs were fused medially along their whole extent. The fibulae appeared slightly larger than normal, the left fibula being more intimately fused with its tibia (fig. 3). No other marked abnormalities occurred in the bony structures. The double knee-joint was practically immobile except for a very slight action in the caudocephalic direction.

\section{Myology}

The muscles of the left lateral leg, thigh, and hip regions were normal; those of the right thigh also appeared normal except for a somewhat smaller size. 
In the hip region of the two extra legs there occurred only a very few small muscles that passed down to the thigh. These muscles were inserted along the proximal portions of the two femurs and seemed to represent only remnants. There was a layer of superficial fascia over the whole of this muscle mass. Some atrophic vestigial muscles covered the popliteal fossae extending up over the distal two-thirds of the two femurs and down well over the ventral portion of the knee-joint. They were better developed on the left member than on the right. The space between the two femurs was occupied by an artery, a vein, a large nerve, and an abundance of loose connective tissue. The two legs of the extra pair were bound together by a superficial layer of fascia and the integument. There were two very distinct tendons of Achilles; the one of the left leg was more pronounced, and it was stretched so tight as to permit only very little movement of the left foot. The right foot was more free to move. The flexor digitorum brevis tendons were very distinct on the feet, but none of the muscles could be found. No muscles occurred beyond the extreme proximal ends of the fused tibiae; there was an enveloping layer of superficial fascia along their entire length.

The ligamentum nuchae was the only abnormal structure observed cephalad of the diaphragm. This was a very thick, round ligament rather than, as usual, a thin ligamentous raphé.

\section{Splanchnology}

The stomach, small intestines, liver, gall-bladder, spleen, and pancreas were unpaired and apparently normal.

The large intestines were double; one colon was very much distended and lay ventrad and to the right of a smaller colon (figs. 6, 7, and 8). The former had very short ascending and transverse portions, but a long descending portion which was constricted in the middle. This constriction produced two large sacculations, the caudal being the more distended. The wall of this portion was rigid and brittle, apparently lacking muscle constituents. This larger colon passed through the right pelvic 
mouth and opened into the vagina of the right side, thus contributing to the formation of a cloaca. The smaller colon of the left side had neither teniae nor sacculations; and there were practically no corresponding ascending or transverse portions. It joined a normal rectum which ended in a normal anus; it was on the whole more nearly normal than the right colon. Feces were found in both colons, and there were no adhesions or constrictions that could hinder either from functioning.

The iliocolic portion of the small intestine was slightly enlarged, and at this point of enlargement the two colons anastomosed with each other and with the small intestine (fig. 6). Each colon had a caecum with an appendix. The right caecum was the larger and, excepting its increased size and its associated appendix, it seemed normal. This appendix was a constricted apical portion of about $1.5 \mathrm{~cm}$. in length (fig. 6). The left eaecum was very short, being about $1 \mathrm{~cm}$. long. Its appendix had a smaller diameter than that of the right and was about three times as long (fig. 7). It was sharply folded at four distinct points into a compact structure.

The single ileocolic valve was relatively large and covered both colic orifices, but was thickened in that portion overlying the right orifice (fig. 8). Its opening was directed somewhat laterally and gave vent nearly directly into the left colon. At a point immediately distal to the valve the lumens of the two colons united. On account of the thickening of one side of the valve, the connection between the lumens of the right colon and the small intestine was thrown to the left, somewhat toward the smaller colon. The caecocolic orifices of both colons were apparently normal (fig. 8). It may be of interest to note that there were ten persimmon seeds and a few whole grains of corn in the right colon. The great enlargement of the right colon may find its explanation in a gradual distention by fecal contents which could be only slowly voided due to lack of peristalsis following the paucity or lack of smooth muscle.

On the right side the larger colon, the urethra, and the vagina had a common exit chamber, forming a cloaca (fig. 12). The right rectum formed the largest part of this chamber, and on 
this account the orifices of the vagina and the urethra seemed to empty into it at a point about $3 \mathrm{~cm}$. cephalad of the common external opening, the vagina on the medial and the urethra on the lateral sides, respectively.

The external genitalia of that side were slightly smaller than those of the left, but had a generally normal appearance.

\section{The urogenital system}

The single kidney was situated on the left side. No trace of even a vestigial kidney could be found on the opposite side. This lone kidney, located at the usual level, was considerably larger and more spheroidal than normal (fig. 9). It received a large renal vein from the left side of the inferior vena cava; and slightly dorsad and caudad of this point it received a renal artery from the abdominal aorta. Midway between the latter and the pelvis of the kidney the renal artery divided into two, one entering dorsally and the other, after curving around the renal vein, entering ventrally and cephalicly to it. Before entering the pelvis the renal vein gave off a branch that coursed laterally over the ventrocaudal portion of the kidney to the left ovary and oviduct. A single large ureter passed caudally to empty into the left urinary bladder in a normal way (fig. 10). The minute anatomy of this kidney was perfectly normal. Cephalad of the kidney, and in their proper positions, occurred two adrenals (fig. 9).

Of the two urinary bladders the left was apparently normal, except that it was slightly displaced to the left. The displacement was due chiefly to the presence of the greatly distended right colon. This bladder was completely collapsed. Its urethra was normal, emptying by means of the left vagina (fig. 10). The right urinary bladder was rigid and distended. It was composed of brittle tissue apparently like that of the larger colon. It was obviously smaller than the left bladder when the latter had become distended. At its cephalic end there was a narrow circular area $(3 \mathrm{~mm}$. in diameter) of very delicate tissue simulating a membrane, which yielded on the slightest pressure (fig. 
11). There was no vestige of a ureter in connection with this bladder. Its urethra had about twice the normal diameter, and was composed of the same kind of brittle tissue as the bladder. A medial longitudinal section of the bladder revealed a lining of elastic tissue that was hard to peel off and that had the macroscopic appearance and general consistency of a thin plate of cartilage. Irregular partitions extended from the walls forming two large pockets at the cephalic and caudal ends of the bladder, respectively (fig. 11). Between these and in the central portion there were about ten smaller pockets. Along the entire ventral wall there was a space between this cartilage-like lining and the wall of the bladder which was continuous with the lumen of the urethra (fig. 11). The urethra had a very thick wall and emptied into the cloaca (fig. 12).

\section{The genital organs}

Two ovaries, each with its respective uterine tube (unpaired cornu uteri) leading to a respective uterus (corpus uteri), were situated in their normal positions. The ovary of the left side was flattened and oval in outline; that of the right side was flattened, elongated, and almost crescent-shaped, with a deep longitudinal groove extending over its lateroventral surface. The two uterine tubes extended caudomedially to their corresponding uteri (figs. 12 and 13). The right tube was the shorter and slightly the thicker of the two. The right uterus was about twice as long and thick as the left. The latter presented no peculiarities in its continuation into the vagina of the left side. The right vagina was relatively short; it was continued into the common chamber which formed the cloaca. Both uteri were abnormal to the extent that they were unicornuate.

Four rows of asymmetrically distributed nipples, twelve in number, were present (fig. 14). 


\section{Angiology}

The blood supply of the kidney has been described above. No traces of any blood-vessels that might have corresponded to the right renal artery and vein could be found.

The abdominal aorta and the inferior vena cava remained single throughout their entire course, but they gave off extra branches which supplied the supernumerary structures. The distribution of these two chief vessels and their principal branches is shown in figure 15. The abdominal aorta gave off a right common iliac artery a short distance cephalad of its usual place of branching. The left common iliac was larger than the right and seemed to represent a direct continuation of the abdominal aorta. Its course was in direct line with that of the aorta to a point about $1 \mathrm{~cm}$. caudad of the point of branching of the right common iliac. Here there was a gentle curve to the left, the main portion being continued as the left external iliac which proceeded down the left lateral leg as the femoral artery. Slightly caudal to the beginning of this curve on the left common iliac just mentioned, and on the outside of it, a large branch came off which supplied the two extra legs. Very close to the origin of this larger branch there was a small branch which went to the left urinary bladder; while just caudal to this a larger one came off and divided into two, the medial representing the caudal (middle sacral) and going to the tail, the lateral going to the structures in the left pelvic cavity and probably representing the left internal iliac artery.

One principal artery and one principal vein supplied the two extra legs. The plan of the arterial supply is represented in figure 16; that of the venous supply is practically indentical. The vessels continued their course caudally between the two femurs, giving off two small branches, one on each side, just distal to the heads of the femurs, to supply the scanty muscles and fascia of that region. No other branches were discernible cephalad of a level about $2 \mathrm{~cm}$. proximal to the knee-joint. At this point, however, both the artery and the vein divided into one medial and two lateral branches, the two lateral branches of 
each vessel passing distally to the lateral sides of the fused tibiae and finally coming around on the dorsal side to form an anastomosing arch over the distal portion of the tibiae in the region of the ankle. From this arch sprang two main arteries and veins which passed on to supply the feet, the right set to the right foot and the left set to the left foot. Two medial smaller branches arose from the arch and supplied the structures in the immediate vicinity. The medial branch (fig. $16 \mathrm{M}$ ) of the principal vessels mentioned above represented a terminal branch. The medial artery and vein passed distally along the ventral line of fusion of the two tibiae where they became resolved into branches that supplied the structures of the ventral portion of the fused legs. The lateral branches supplied the structures of the lateral and dorsal surfaces. The venous system of the supernumerary legs paralleled the arterial system throughout its entire course.

Numerous lymph nodes were found scattered throughout the abdomen. Just cephalad of the kidney occurred the two largest nodes. The smaller nodes were relatively more abundant along the inferior vena cava and the abdominal aorta. Those of the paired pelvic cavities were rather large and numerous. A large bean-shaped lymph node, about $1 \mathrm{~cm}$. in length, was situated at the level of the stifle-joint on the ventral side. This probably represented a composite popliteal node and was apparently the only lymph node of the two extra legs.

\section{Neurology}

A large nerve accompanied the principal artery and vein of the two extra legs. This nerve presented an oval cystic enlargement, macroscopically suggestive of a ganglion, at the point where it entered the double leg, just distal to the heads of the two femurs. The nerve passed dorsal to the blood-vessels, accompanying them as far as they went, and then accompanying the terminal or medial branch down over the midline of the double stifle-joint. As the nerve passed the latter point it presented a gradual cone-shaped enlargement and, turning laterally and dorsally around the medial condyle of the head of the 
right tibia, ended abruptly in the skin (fig. 16). On the external surface of the skin this termination presented a roughened scarlike appearance, the size of which was approximately that of the diameter of the nerve. Three smaller scar-like patches occurred below, and slightly medial to the principal one. No nerve fibers could be traced within the skin. The whole appearance of this nerve termination seems exactly what might have been expected if the nerve had penetrated the skin and its external part had subsequently sloughed off, thus leaving a scar with the nerve firmly attached. The proximal part of this nerve was attached to the right wall of the cavity through which it coursed to the extra legs in company with the two main bloodvessels. This attachment was made by strands of tissue chiefly to the middle portion of the small opening. The portion of the nerve from the cyst forward consisted of a hollow, circular strand of tissue that tapered down almost to nothing. There remained no connection with the spinal cord. This nerve probably represented fused right and left medial sciatic nerves.

\section{CONCLUSIONS}

Viewing the double portion of this dog, it is seen that the left component is more fully developed and that it is nearly in normal position, while the right component is entirely at the right of the median plane. The blood-vascular, the digestive, and the urogenital systems, excepting the kidney, and the fusions and articulations of the pelvic limbs, all consistently support an interpretation of this monster in terms of a side-to-side pelvic fusion of twin primordia, with complete resorption of the prediaphragmatic portions. A variant of this interpretation might be based upon the supposition that an original unpaired embryonic disc suffered a caudal splitting to the point including the primordia of the pelves. It is not possible with the available data to decide finally between the suggested alternatives of rusion and splitting. However, the mixed character of the abdominal viscera (e.g., single kidney, double colon) seems to favor the interpretation of fusion rather than of splitting. The 
one chief objection to the interpretation of lateral, as opposed to dorsoventral, fusion is the presence of the unpaired sciatic nerve of the extra two legs. It the interpretation of lateral fusion is accepted, then the compound sciatic nerve seems to be greatly displaced. The sciatic nerve normally passes through the pelvic mouth and then courses laterally over the acetabulum on down the leg. The sciatic nerve of the right and left lateral legs followed this normal course. The fused sciatic nerves of the supernumerary limbs, however, entered the pair by a single root, having passed thither between the two medial acetabula, and not, as normally, through their respective pelvic mouths. The apparently ectopic position of the fused sciatic nerves can be explained on the very probable supposition that the primordia of the originally paired medial sciatic nerves fused before the medial components of the pelves had developed beyond their blastemal stage. This explanation becomes the more plausible when it is recalled that the fused sciatic nerves had suffered degeneration at their proximal ends, due in all probability to pressure here following the further development and subsequent fusion of the two medial components of the right and left pelves.

This dog belongs in the category of duplicate monsters designated dipygus dibrachius tetrapus, and corresponds in general to the six-legged rat recently described by Conrow ${ }^{1}$ and more closely to certain human monsters described under this designation by Broman. ${ }^{2}$

\section{LITERATURE CITED}

1 Conrow, Sara B. 1917 A six-legged rat. Anat. Rec., vol. 12, p. 365.

2 Broman, Ivar 1911 Normale und abnorme Entwicklung des Menschen. Bergmann, Wiesbaden, S. 190. 


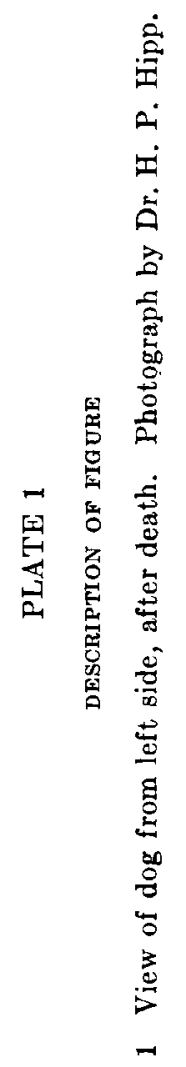


空

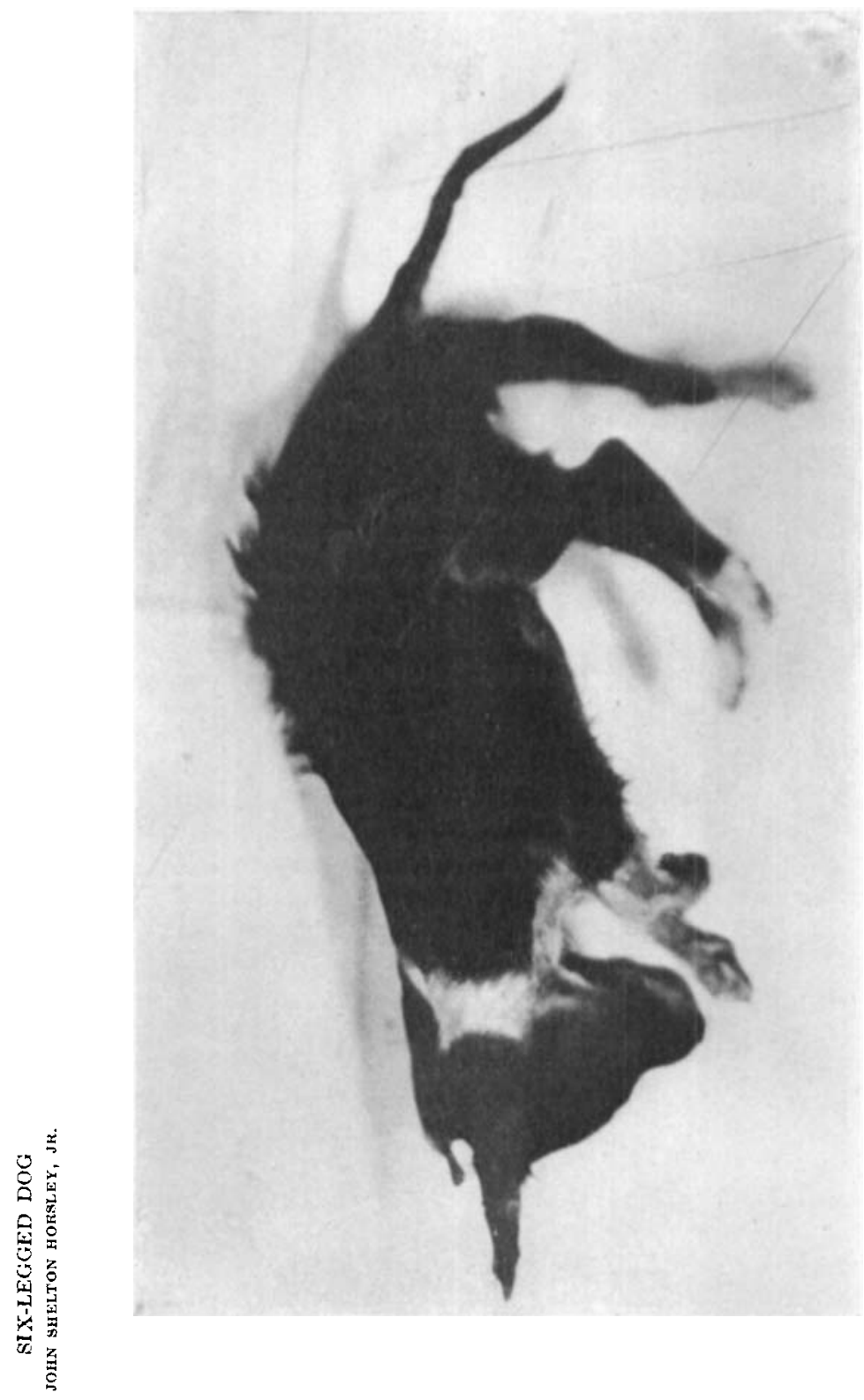

15

THE ANATOMICAL RECORD, YOL. 19 , No. 1 
PLATE 2

DESCRIPTION OF FIGURES

2 and 3 Roentgenogram by Dr. H. P. Hipp. 


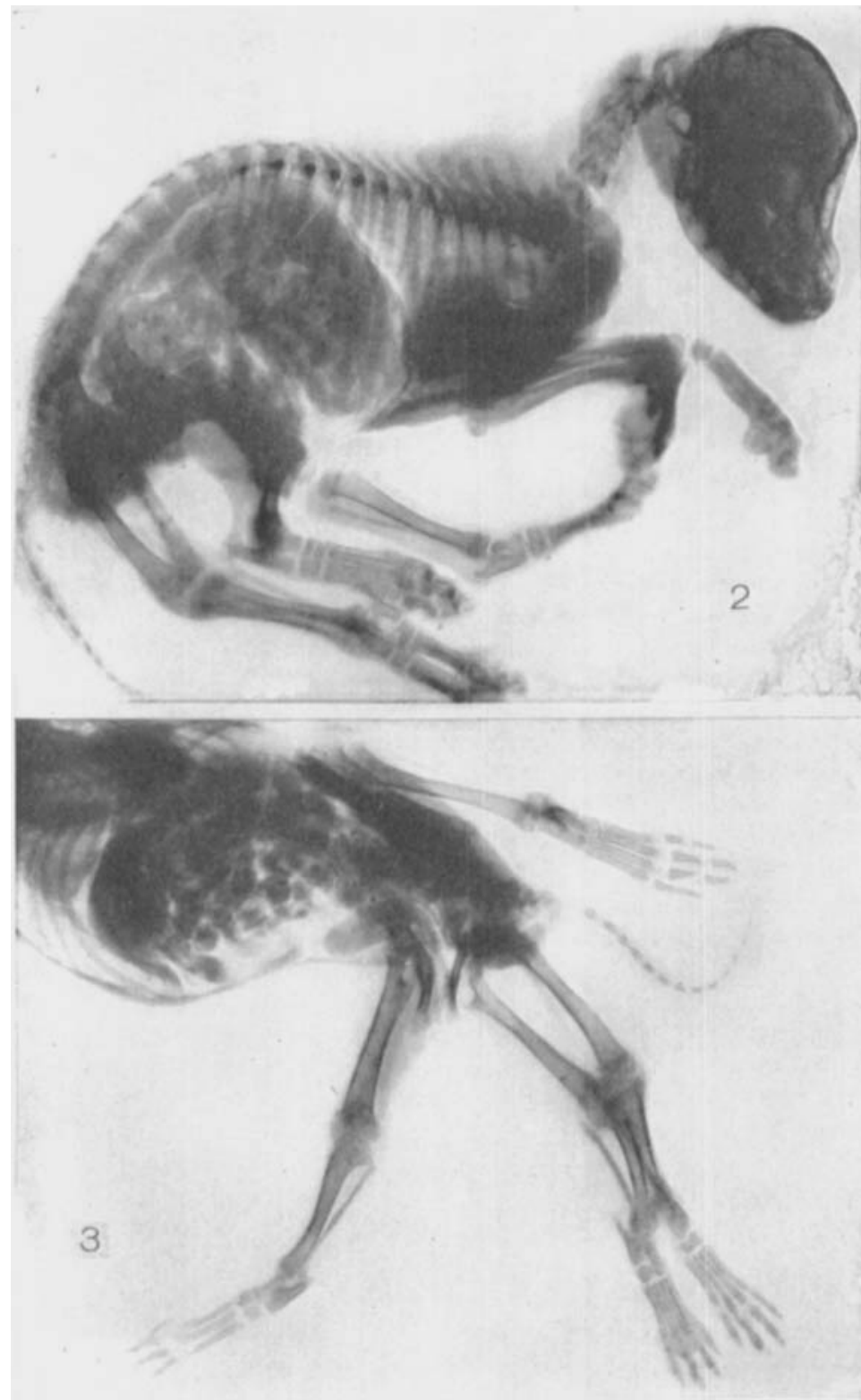


PLATE 3

DESCRIPTION OF FIGURES

4 Drawing of the double bony structures in the pelvic region viewed from the right side. $A$, left medial femur; $B$, right medial femur; $C$, left medial tuber ischii; $D$, right medial tuber ischii; $E$, right lateral tuber ischii; $F$, right lateral femur; $G$, left lateral femur; $H$, right lateral ilium; $I$, left lateral ilium; $J$, fused medial ilia; $K$, fifth lumbar vertebra; $L$, caudal vertebrae; $M$, right deformed sacrum; $N$, small piece of bone articulating with right deformed sacrum and right lateral ilium (possibly remnant of a second vertebral column). Four-fifths life size. Drawn by Helen Lorraine.

5 Drawing of the double bony structures in the pelvic region from a caudoventral aspect. $A$, left medial femur; $B$, right medial femur; $C$, mouth of right pelvis; $D$, central point of the fusion between the right and left pelves, which extends along the pubo-ischial symphysis of each; $E$, left lateral obturator foramen; $F$, right lateral femur; $G$, lef lateral femur; $H$, sixth lumbar vertebra. Four-fifths life size. Drawn by Helen Lorraine. 

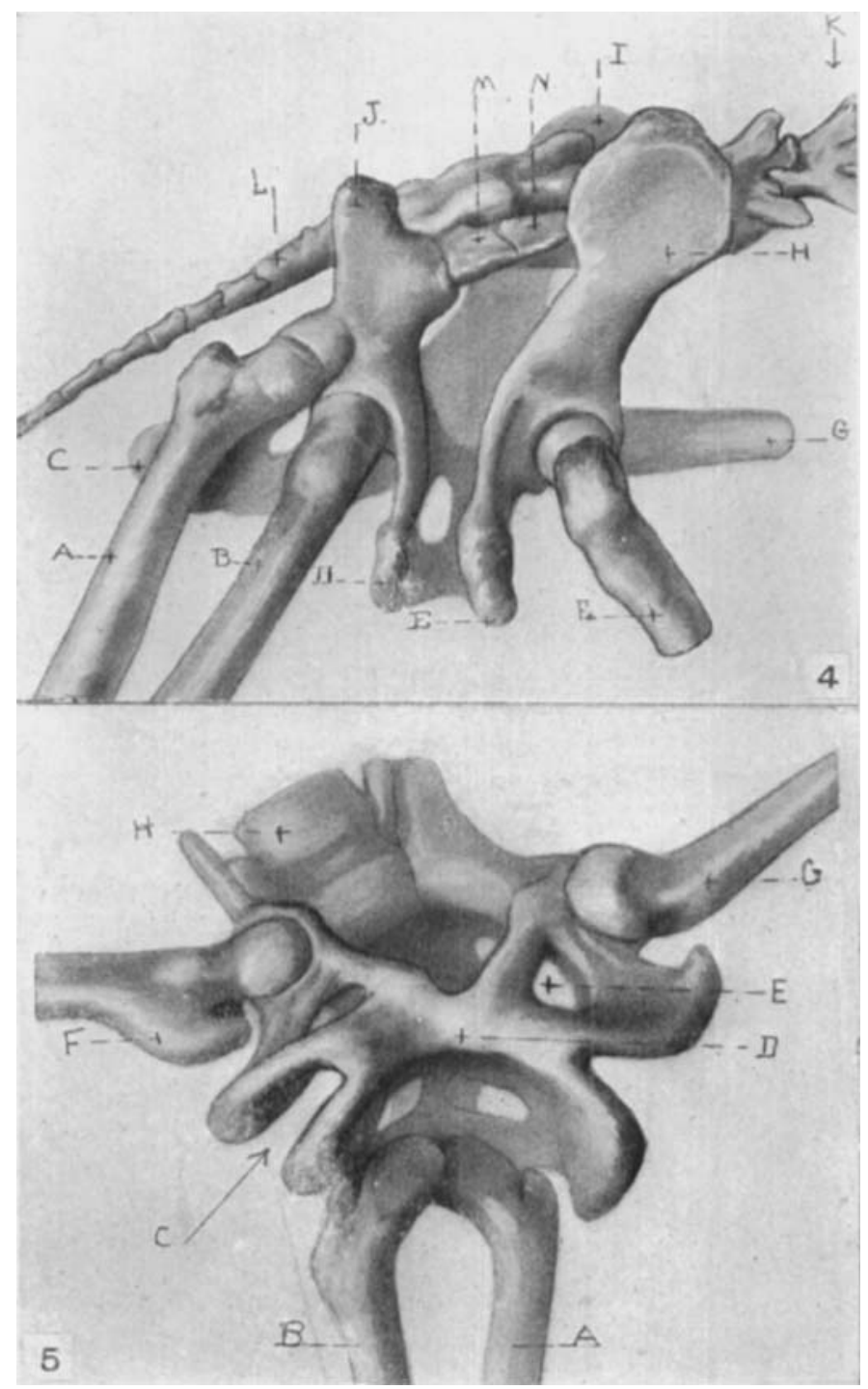


\section{PLATE 4}

\section{DESCRIPTION OF FIGUBES}

6 Drawing of the anastomosis of the small intestine with the right and left colons from a right ventral aspect. The right caecum with its associated appendix is also shown. The portion of the right colon here shown represents only one of the two sacculations that were present. The sccond was approximately the same size. Four-fifths life size. Drawn by Helen Lorraine.

7 Drawing of the anastomosis of the small intestine with the right and left colons from a left ventral aspect. The left caecum with its associated appendix is also shown. Four-fifths life size. Drawn by Hrlen Lor aine. 
SIX-LEGGED DOG

PLATE 4

JOHN SHFLTON HORELEY, JR.

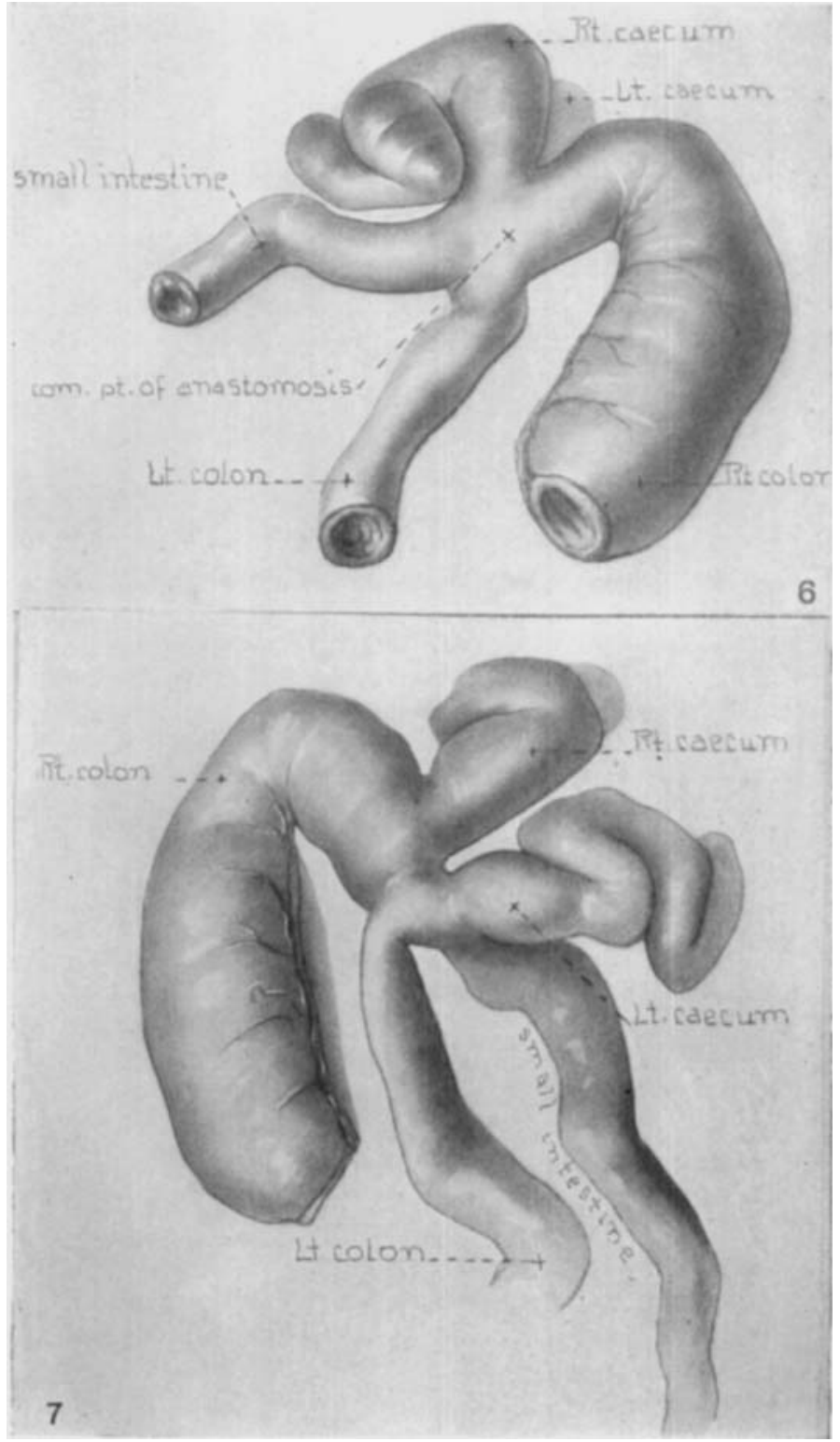


PIATE ;

DESCRIPTION OF FIGURES

8 Drawing of the ileocolic valve from the right side. The ileum and right colon are slit open longitudinally. Four-fifths life size. Drawn by Helen Lorraine.

9 Drawing of ventral view of kidney with its blood-supply, showing also the two adrenals. $K$, single kidney of left side; $L$ and $L^{\prime}$, left and right adrenals; $U$, single ureter leading to left urinary bladder; $A$, abdominal aorta; $V$, inferior vena cava; $R$ and $R^{\prime}$, renal vein and artery; $P$, phrenico-abdominal vein. Branch of renal vein to left ovary and uterine tube not shown in this drawing. Fourfifths life size.

10 Drawing of left urinary bladder partially distended. The bladder is in a position to show the ureter emptying on the dorsal surface. Four-fifths life size. 
SIX-LEGIGED DOG

PLATE 5

JOHN SHELTON HORSLEY, JR.

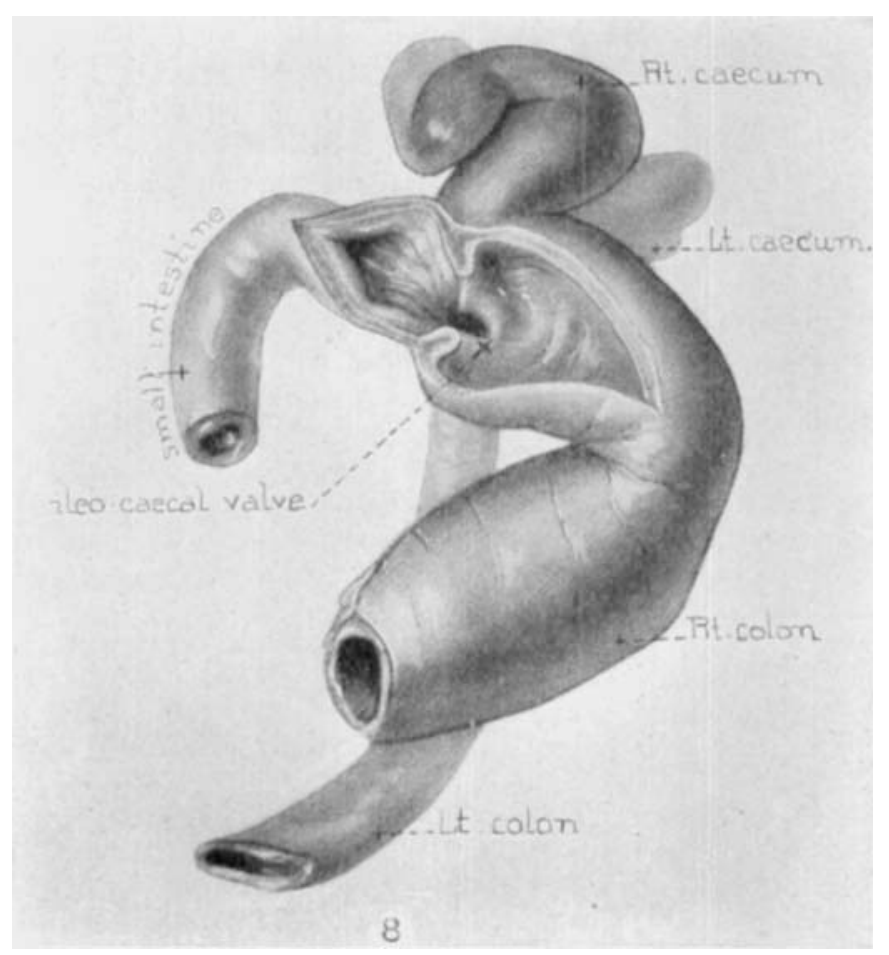

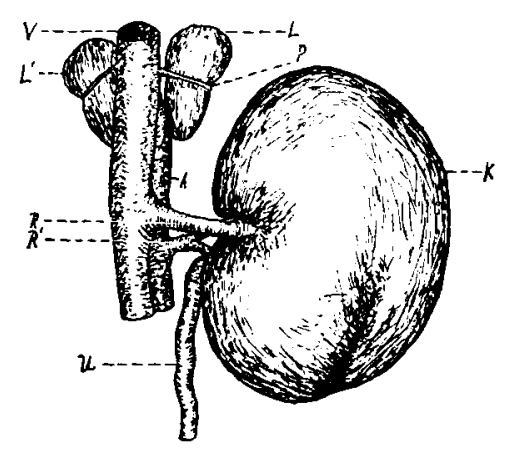

9

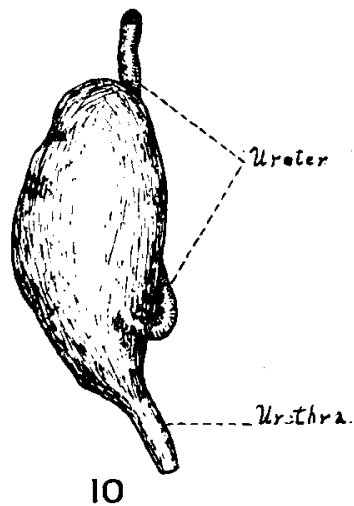

10 


\section{PLATE 6}

\section{DESCRIPTION OF FIGURES}

11 Drawing of the interior of the right urinary bladder from a dorsal aspect. It is slit open dorsally in the longitudinal plane. Four-fifths life size. Drawn by Helen Lorraine.

1.2 Drawing of the cloaca and genital organs of the right side. Cloaca is slit open. $O$, right ovary; $U t$, right uterine tube (unpaired horn of right uterus); $U$, body of right uterus; $U r$, urethra from right bladder; $E$ and $E^{\prime}$, orifices of uterus and urethra into common exit chamber forming the cloaca; $C$, right colon. t'our-fifths life size.

13 Drawing of the genital organs of the left side. Vulva, vagina, and uterus (in part) are slit open. $O$, left ovary; $U t$, left uterine tube; $U$, left uterus; $E$, cxternal uterine orifice; $H$, hymen; $E^{\prime}$, external urethral orifice; $V$, vulva; $M$, central projection of fold of mucous membrane which conceals the clitoris; $F$, fossa clitoridis; $L$, labia vulvae. Four-fifths life size. 
SIX-LEGGED DOG
JOHN SHELTON HORSEY, IR.

PLATE 6

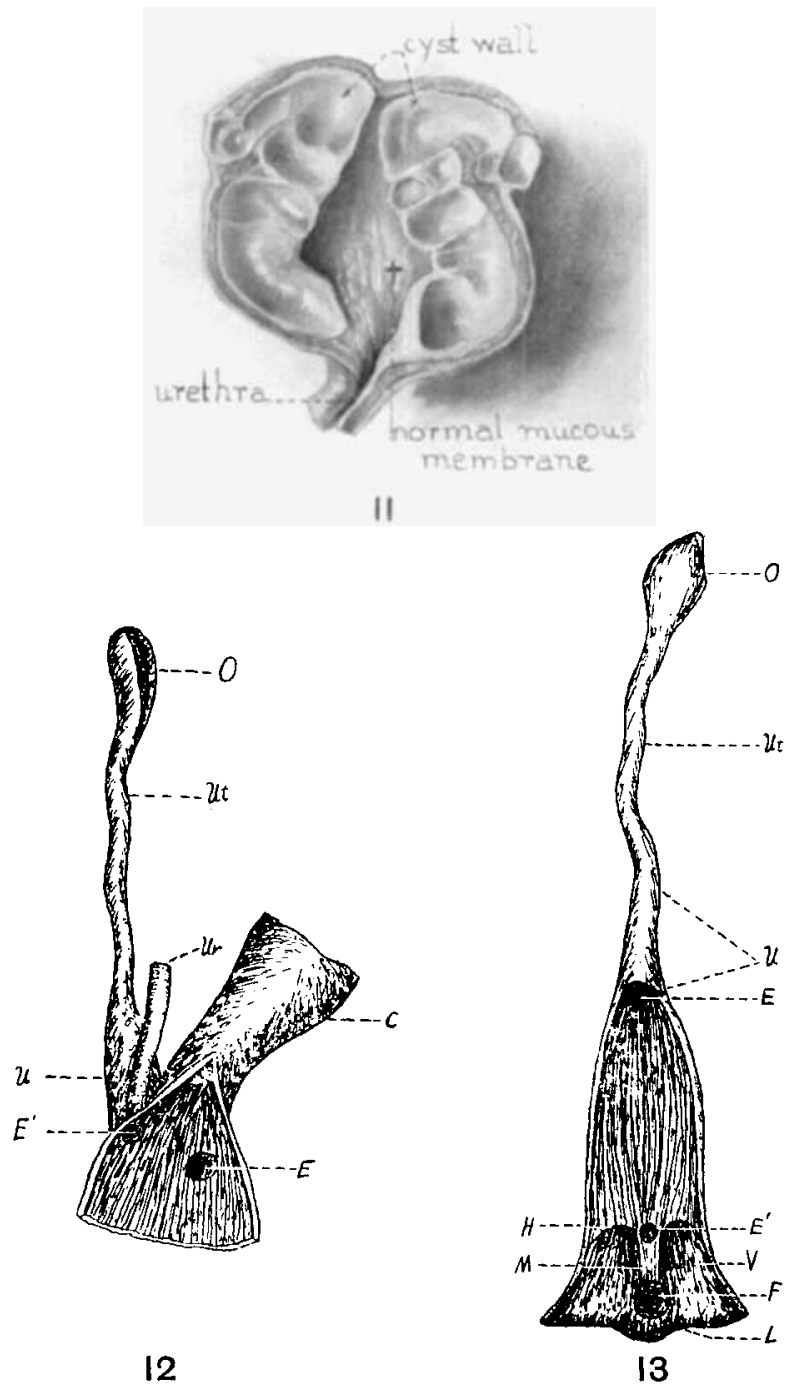

25 


\section{PLATE 7}

\section{DESCRIPTION OF FIGURES}

14 Diagram of the arrangement of the nipples. Each small black dot represents a nipple. One-fifteenth life size.

1.5 Diagrammatic drawing of the distal portion of the abdominal aorta and its branches seen from a ventral view. $A$, abdominal aorta; $R$.C.I., right common iliac; R.E.I., right external iliac; R.F., right femoral to right lateral leg; L.E.I., left external iliac; L.F., left femoral to left lateral leg; D.L., artery to extra pair of legs; $C$, caudal artery to the tail; $a$ and $a^{\prime}$, arteries to neighboring lymph nodes and other structures; $b$, artery to dorsal abdominal wall; $c$, artery to right colon; $e$ and $e^{\prime}$, arteries to structures in the right and middle portions of the pelvic cavity; $f$, artery to structures in the right portion of the pelvic cavity (probably right internal iliac); $g$, artery to left urinary bladder; $h$, artery to left ventral abdominal wall (probably left deep epigastric); $i$, artery to structures of left pelvic cavity. By pelvic cavity above is meant that portion enclosed between the lateral components of both the right and left pelves. Veins accompanied the arteries.

16 Diagram of the arteries and nerve of the extra pair of legs as seen from a ventral view. The nerve ran immediately behind the main artery, but in the diagram it is shoved to the right. $A$, point of emergence of artery between the heads of the two femurs; $C$, cystic enlargement on the unpaired sciatic nerve; $B$, the curve of the sciatic nerve around the medial condyle of the right medial tibia; $E$, termination of the scjatic nerve in the skin; $D$, point about $2 \mathrm{~cm}$. above proximal end of fusion of two medial tibiae; $L$, lateral branch which passed around the left medial leg (also level at which the sciatic nerve passed behind the stifle-joint); $R$, lateral branch which curved around the right medial leg; $M$, medial branch which ran along dorsal line of fusion of the two medial tibiae; Ar, anastomosing arch on the dorsal surface of the fused medial tibiae in the region of the ankles, formed by the two lateral branches; $F$ and $F^{\prime}$, branches to right and left feet; $m$, small branches to the skin, fascia and scanty muscles; $t$. terminal branches of the medial branch supplying neighboring skin, fascia, and scanty muscles. Veins accompanied the arteries. 


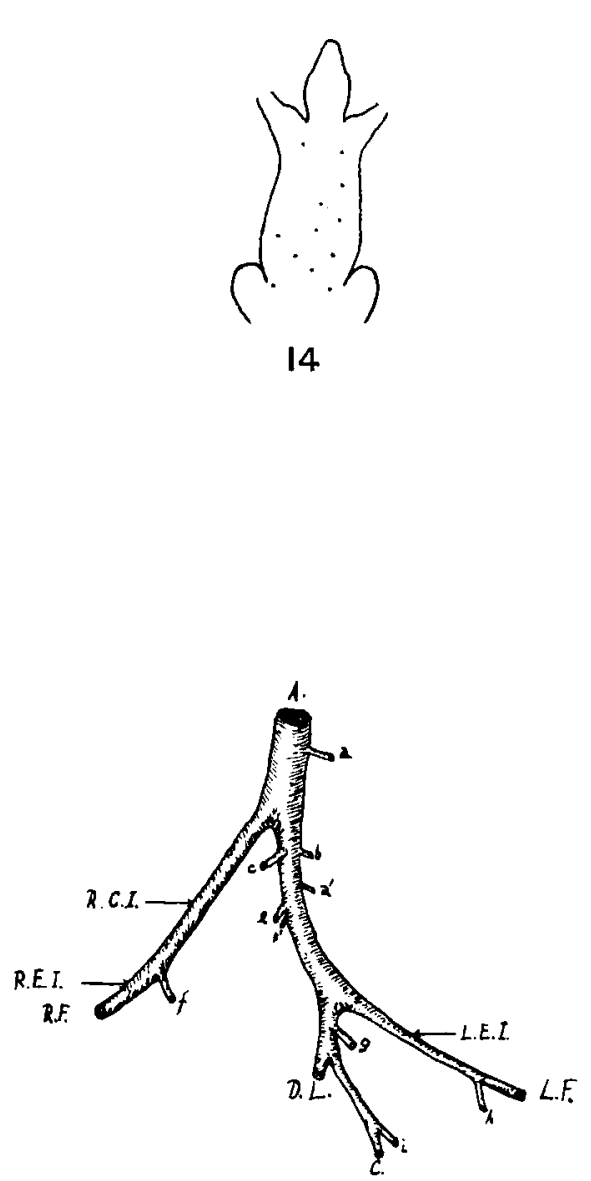

15

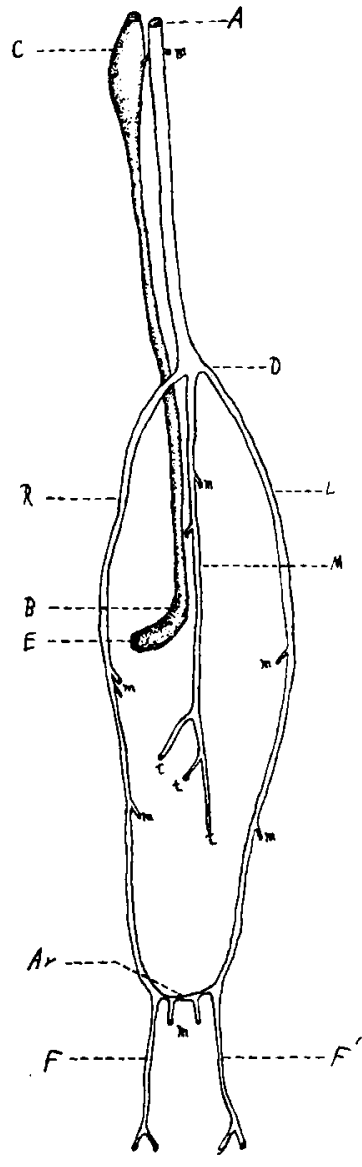

16 